\title{
LIVE BETTER ADDING AVOCADO FRUIT TO YOUR DAILY DIET
}

\author{
Lydia Ferrara \\ Department of Pharmacy, University of Naples Federico II, \\ Via Domenico Montesano 49, 80131 Naples, Italy
}

\begin{abstract}
Avocado is a fruit rich in nutrients of high biological value capable of providing wellbeing to our body. The addition of the fruit to a main meal has shown that the right balance, in the lipid component, between saturated, monounsaturated and polyunsaturated fatty acids helps to influence post-ingestion satiety for a subsequent period of 3 hours and 5 hours, with a decrease of glucose and insulin in the blood of overweight and moderately obese adults.

Satiety is an important factor in weight management and in addition, the replacement of saturated fatty acids in the diet with unsaturated ones has shown beneficial effects on the cardiovascular system

The presence of carotenoids such as lutein has been shown to be useful for preventing vision disorders and improving cognitive abilities especially in elderly subjects.

For a long time avocado seed was considered a waste material, but current research has shown that avocado seeds can improve hypercholesterolemia, and be useful in the treatment of hypertension, inflammatory conditions and diabetes, being rich of phenolic compounds, which have beneficial effects on health.
\end{abstract}

Keywords: Tropical fruit; chemical composition, food, oil, nutraceutical

\section{INTRODUCTION}

Avocado is the fruit of the Persea americana Mill or Laurus persea L., a tree belonging to the Lauraceae family native to Central America and Mexico.

The fruit has a pear-like shape and can reach $25 \mathrm{~cm}$ in length and $1.4 \mathrm{~kg}$ in weight: the avocado peel is thick, smooth or wrinkled, ranging in color from dark green to deep purple; the pulp is not very sweet, it is compact, smooth and creamy due to the abundant presence of fats, and of a greenish-yellow color; the single seed, on the other hand, of large dimensions and woody consistency, is brown, heavy and with a typical "drop" profile. The fruit must have the stalk attached: its absence indicates that the fruit was stolen at night by plucking it and not cutting it by day with scissors like a good producer does. The lack of stalk will also allow pathogens to enter and the avocado will begin to decompose and the pulp will turn black.
Each fruit has a label on the skin indicating the manufacturer's brand and serious companies certify with a specialized international company, compliance with food safety and hygiene standards.

Avocados, like pears or peaches, have two ripening processes: the first on the tree that goes from the moment they are born, until the day they are ready for harvesting and have produced the necessary amount of oil,about $8 \%$, that gives the flavor. When ripe for harvesting, however, they are still green and hard and not suitable for consumption. The second ripening process takes place after harvesting, waiting for the peel to darken and the avocado to be no longer hard to the touch, avoiding both exposure to the sun that accelerating the ripening process would cause the fruits to decompose, and avoiding proximity to apples or kiwi. It is very important that the temperature of the cold rooms in which the avocados are stored is at least $5^{\circ} \mathrm{C}$ : lower temperatures burn the fruit and the pulp turns black when consumed.

There are more than one hundred varieties of avocado, but the best known and most widespread is the Hass, originally from California, with thick, wrinkled skin, dark green when ripe with creamy pulp and fiber-free, easy to skill [1].

$100 \mathrm{~g}$ of avocado provides about 200 Calories. Contains Water, Proteins, Fibers, Lipids (unsaturated: oleic, palmitoleic, linoleic, alpha-linolenic, arachidonic acid; saturated: palmitic acid); Vitamins (B1, B2, B3; C, E, D); Minerals (iron, phosphorus, potassium, sodium, calcium, magnesium, zinc); Carotenoids (lutein, zeaxanthin); Folic acid.

In the leaves of the Mexican avocado there is also an essential oil that is a source of estragole and anethole

\section{NUTRITIONAL AND THERAPEUTIC PROPERTIES}

Avocados are rich in nutrients with properties that can favorably affect the energy balance. Some studies have shown how the addition of even one half of avocado to a meal can influence the sense of satiety after ingestion, for a period of 3-5 hours in overweight individuals. The inclusion of avocado also produced a significant reduction in blood insulin levels over a 3-hour postprandial period and this decrease is particularly important for people with insulin resistance and type 2 diabetes.

In fact, it has been shown that the biological signaling of satiety by insulin in the overweight population is 


\section{International Journal of Engineering Applied Sciences and Technology, 2020 \\ Vol. 5, Issue 4, ISSN No. 2455-2143, Pages 343-347 \\ Published Online August 2020 in IJEAST (http://www.ijeast.com)}

attenuated, with serious consequences for the overeating taken with subsequent meals and therefore the introduction of avocado in the main meal represents a simple artifice food with beneficial purposes[2,3].

The monounsaturated fats present in the fruit not only reduce the sense of appetite but contribute to the maintenance of normal blood fluidity, reducing LDL cholesterol levels for the benefit of HDL cholesterol and maintaining optimal blood sugar levels after a meal. The benefit on the cardiovascular system also concerns in particular the balance of blood pressure [4,5]. The presence of omega-3 fatty acids is useful for protecting the nervous system and strengthening the immune system

Taking avocados during pregnancy is particularly indicated, due to the presence of folic acid, which acts by protecting the fetus from some malformations by the nervous system.

Avocado is rich in anti-inflammatory compounds: phytosterols, carotenoids, polyphenols, flavonoids, vitamin $\mathrm{C}$, vitamin $\mathrm{E}$, zinc, selenium. Regular consumption of foods with anti-inflammatory action plays a crucial role in protecting our body from the action of free radicals, thereby preventing inflammatory and joint diseases. Osteoarthritis is a disease that mainly affects people of advanced age and obese and is characterized by a deterioration of cartilage tissues as a result of oxidative and inflammatory stress. Nutrition plays an important role: fruits and vegetables rich in carotenoids are essential to prevent degenerative defects by keeping the joint cartilages in good condition[6-8].

The potassium content is also high in the avocado, which even exceeds that of the banana. It is known that potassium is involved, as an electrolyte, in the water balance and in the maintenance of blood pressure. It also acts by regulating neuromuscular excitability, heart rhythm, osmotic pressure, acid-base balance.

Magnesium is also present in high quantities: in our body it is an essential component for all tissues and cells. Combined with calcium and phosphorus, magnesium is an essential constituent of hydroxyapatite, the structural mineral of bone tissue. Magnesium ions interact mainly with polyphosphate compounds such as ATP, DNA, RNA, intervening in the regulation of the excitability of nerve membranes and muscles, and in synaptic transmission[9].

The fruit pulp has a soft consistency and a high amount of vegetable fats, for this reason it can be an excellent substitute for butter even in vegan pastry.

Avocado oil is extracted from the dried pulp with different methods and is used in food as it is very similar to olive oil. The best quality is obtained by cold pressing or by centrifugation of the pulp so that the organoleptic properties are not lost. The concentration of the components varies according to the ripeness: the fat content reaches a value of $8 \%$ at the time of harvesting the fruit from the tree, while during vegetative ripening it reaches values of $20 \%$ and more depending on the variety. Furthermore, the ratio of unsaturated fatty acids / saturated fatty acids is greatly influenced by the country of origin: fruits from Mexico, Australia, the United States and New Zealand, are characterized by a double oleic acid content compared to palmitic acid; while the fruits from South Americahave a high content of monounsaturated fatty acids compared to polyunsaturated and saturated fatty acids $\lceil 10-12\rceil$.

Avocado is rich in carotenoids including lutein and zeaxanthin which are selectively absorbed in the macula of the eye, where the light is focused on the lens: as the years progress, an integration of these substances is necessary to prevent ocular pathology. , caused by a deficient diet and a low plasma concentration of them[13-17] .

The avocado seed is also edible as it contains various bioactive substances and almost $70 \%$ of the antioxidants of the whole fruit; it contains fatty acids and is used to extract the oil. The abundance of fatty acids, triterpene alcohols, fat-soluble vitamins A-D-E$\mathrm{K}$ and lecithins make it useful for various aesthetic treatments. Applied on the body it is useful for preventing and treating stretch marks, eliminating excess fat and toning the body. Its regenerating properties help the healing processes and at the same time soften the sclerotic tissues. The quality of avocado oil depends on several factors, such as the quality and maturity of the fruit, the extraction technique in relation to the temperature, solvents used and type of storage. Comparing the composition of the oil from the pulp and from the seed it was noted that the lipid content was higher in the pulp than in the seed, while regarding some qualitative parameters such as iodine index, acidity and saponification index, the values were higher in the oil of seeds compared to pulp, due to the presence in it of a greater variety of fatty acids [18]. Avocado oil due to its analytical composition, when used in pharmaceutical formulations on skin wounds, favors the synthesis of collagen, by decreasing the number of inflammatory cells, allowing a rapid healing[19,20].

\section{CONCLUSIONS}

Avocados are distinctive fruits that contain both fat and fiber along with various micronutrients and bioactive phytochemicals. There are various uses in the kitchen: it can be eaten alone, raw, seasoned with oil, pepper, salt and lemon, or added to salads; it can also serve as an accompaniment to wraps or sandwiches, or be used for making desserts; very well known is the "guacamole sauce" used as a condiment on vegetables, meat and fish.

The avocado seed is edible and rich in properties, containing various bioactive substances and almost $70 \%$ of the antioxidants of the whole fruit and is used in traditional medicine to treat a wide range of diseases. The seed, after removing the brown film that covers it, is placed in a plastic bag and then crushed with a hammer: the fragments are blended or it is 


\section{International Journal of Engineering Applied Sciences and Technology, 2020 Vol. 5, Issue 4, ISSN No. 2455-2143, Pages 343-347 \\ Published Online August 2020 in IJEAST (http://www.ijeast.com)}

possible to grate the seed directly, adding it to salads, soups, stews or in guacamole sauce.

Numerous studies have investigated the association between avocado consumption and health effects of the cardiovascular system, weight management, blood glucose control In particular, potassium and lutein may help promote normal blood pressure. and help control oxidative / inflammatory stress. A moderate consumption of avocado, in fact, seems associated with a better metabolism of lipids, with a reduction in total and LDL cholesterol and an increase in the levels of good cholesterol, HDL. This fruit also has a good content of polyphenols, phytocompounds that in in vitro studies have shown anti-inflammatory and antioxidant activity. Regular consumption of foods with anti-inflammatory action plays a crucial role in protecting our body from the action of free radicals, thus preventing inflammatory joint diseases.

\section{REFERENCES}

1-Lu QY., Zhang Y., Wang Y., Lee RP., Gao K., et al. California Hass Avocado: Profiling of carotenoids, tocopherols, fatty acids, and fat content during maturation and from different growing areas. J. Agric. Food Chem. 2009;57:10408-10413

2- Wien M., Haddad E., Oda K. Sabatè J.A randomized $3 \times 3$ crossover study to evaluate the effect of Hass avocado intake on post-ingestive satiety, glucose and insulin levels, and subsequent energy intake in overweight adults. Nutr J 2013; 12: 155-164 doi: org/10.1186/1475-2891-12-155

3- Flint A.,Gregersen N.,Gluud L.,Moller B.,Raben A., et al. Association between post prandial insulin and blood glucose responses, appetite sensations and energy intake in normal weight and overweight individuals: A meta-analysis of test meal studies British J Nutr 2007;98(1):17-25. Doi:10.1017/S000711450768297X

4- Alvizouri-Munoz M., Carranza-Madrigal J., Herrera-Abarca J. E., Chavez-Carbajal F., AmezcuaGastelum JL Effects of avocado as a source of monounsaturated fatty acids on plasma lipid levels. Arch. Med. Res. 1992;23:163-167

5- Paniagua JA., de la Sacristana AG., Sanchez E., Romero I., Vidal-Puig A., et al. A MUFA-rich diet improves postprandial glucose, lipid and GLP-1 responses in insulin-resistant subjects. J. Am. Coll. Nutr. 2007b;26(5):434-444

6- Iannone F., Lapadula G. The pathophysiology of osteoarthritis. Aging Clin Exp Res 2003;15:364-72.

7- Rosenbaum CC, O'Mathúna DP, Chavez M, Shields $\mathrm{K}$, Antioxidants and antiinflammatory dietary supplements for osteoarthritis and rheumatoid arthritis Altern Ther Health Med, 2010; 16( 2): 32-40

8- Dinubile NA. A potential role for avocado-and soybean-based nutritional supplementation in the management of osteoarthritis: A review. Phys. Sportsmen. 2010;38(2):71-81

9- Ayuk J., Gittoes .J. Contemporary view of the clinical relevance of magnesium homeostasis. Ann Clin Biochem 2014; 51 (2): 179-88.

10- Forero-Doria O., Flores M., Vergara C.E., Guzman L. Thermal analysis and antioxidant activity of oil extracted from pulp of ripe avocados. J. Therm. Anal. Calorim. 2017;130:959-966. doi: 10.1007/s10973-0176488-9

11- Galvão MDS., Narain N., Nigam N. Influence of different cultivars on oil quality and chemical characteristics of avocado fruit. Food Sci. Technol. 2014;34:539-546. doi: 10.1590/1678457x.6388

12- Yanty NAM., Marikkar JMN., Long K. Effect of varietal differences on composition and thermal characteristics of avocado oil. J. Am. Oil Chem. Soc. 2011;88:1997-2003. doi: 10.1007/s11746-0111877-X

13- Caepentier S., Knausi M., Suhi M. Associations between Lutein, Zeaxanthin, and age-related macular degeneration: an overview . Crit. Rev. Food Sci. Nutr. 2009; 49 : 313-326

14- Johnson EJ, Maras JE, Rasmussen HM, Tucker KL. Intake of lutein and zeaxanthin differ with age, sex, and ethnicity. J Am Diet Assoc. 2010; 110(9):1357-62. doi: 10.1016/j.jada.2010.06.009

15- Cho J., Hankinson SE., Rosner B., Willett WC., Colditz CA. Prospective study of lutein/ zeaxanthin intakes and risk of age-related macular degeneration. Am. J. Clin. Nutr. 2008;87:1837-1843

16- Roberts RL., Green J., Lewis B. Lutein and zeaxanthin in eye and skin health. Clin. Dermatol. 2009; 27: 195-201

17- Unlu N., Bohn T., Clinton SK., Schwartz SJ. Carotenoid absorption from salad and salsa by humans is enhanced by the addition of avocado or avocado oil. J. Nutr. 2005;135:431-436.

18- Bora PS., Narain N., Rocha RV., Paulo MQ. Characterization of the oils from the pulp and seeds of avocado (cultivar: Fuerte) fruits. Grasas Aceites. 2001;52:171-174.

19- Nayak BS., Raju SS., Chalapathi RAV. Wound healing activity of Persea americana (avocado) fruit. A 
International Journal of Engineering Applied Sciences and Technology, 2020

Vol. 5, Issue 4, ISSN No. 2455-2143, Pages 343-347

Published Online August 2020 in IJEAST (http://www.ijeast.com)

preclinical study on rats. J. Wound Care. 2008; 17(3):123-125.

20- de Oliveira AP, de Souza Franco E., Rodrigues Barreto R., Cordeiro DP, de Melo RG, et al. Effect of semisolid formulation of Persea americana Mill(Avocado) oil on wound healing in rats. Evidence-

Based Complementary and Alternative Medicine 2013; article ID 472382 p 8 doi:org/10. $1155 / 2013 / 472382$ 
International Journal of Engineering Applied Sciences and Technology, 2020 Vol. 5, Issue 4, ISSN No. 2455-2143, Pages 343-347

Published Online August 2020 in IJEAST (http://www.ijeast.com) 